\title{
O escritor e o limiar
}

\section{Lucius de Mello*}

Universidade de São Paulo (USP) | São Paulo, Brasil

luciusdemello@uol.com.br

Nossa mente é porosa para o esquecimento; eu mesmo estou falseando e perdendo, sob a trágica erosão dos anos, os traços de Beatriz.

(Jorge Luis Borges)

Ir às raízes do escrever para tentar entender o processo criativo e as razões que levam um escritor a se perder no labiríntico e borgiano bosque da ficção é um grande desafio. Muitos pensadores e ficcionistas já escreveram brilhante e intensamente sobre esse assunto. Não me atrevo a chegar até lá e, muito menos, ir além...

Escolhi Jorge Luis Borges para abrir o meu depoimento porque em seu livro O jardim das veredas que se bifurcam o autor argentino torna bosque metáfora do texto narrativo. Assim como o fez Umberto Eco em Seis passeios pelo bosque da ficção. Escreve ele:

Bosque é uma metáfora para o texto narrativo, não só para o texto dos contos de fadas, mas para qualquer texto narrativo. Há bosques como Dublin, onde em lugar do Chapeuzinho Vermelho podemos encontrar Molly Bloom [...]. Usando uma metáfora criada por Jorge Luis Borges um bosque é um jardim de caminhos que se bifurcam. Mesmo quando não existem num bosque trilhas bem definidas, todos podem traçar sua própria trilha, decidindo ir para a esquerda ou para a direita de determinada árvore e, a cada árvore que encontrar, optando por esta ou aquela direção. ${ }^{1}$

No meu caso, literalmente, transitei por bosques para escrever o meu primeiro livro de contos, Um violino para os gatos, publicado pela Editora Maltese, em 1995, porque circulava pela zona rural quase todos os dias, entre sítios, fazendas, matas e o cerrado, para cobrir as notícias como repórter do Jornal Nacional da Rede Globo, no interior de São Paulo.

\footnotetext{
* Doutorando em Letras no Programa de Letras Estrangeiras e Tradução da Universidade de São Paulo

${ }^{1}$ ECO, 2002, p. 12.
} 


\section{Arquivo Maaravi}

Foi justamente esse cenário borgiano, revisitado de forma genial por Raduan Nassar, que me apresentou definitivamente a árvore das metáforas. $\mathrm{O}$ campo e os camponeses se tornaram para mim uma poética e inspiradora lavoura. Ali eu colhi, descasquei e semeei as minhas primeiras palavras reinventadas. Portanto, o meu processo criativo, naquela época, estava intensamente conectado ao meu olhar diante do mundo onde eu ora plantava ora arrancava do chão. Por ser repórter de televisão e lidar com imagens, muitas cenas usadas nas minhas reportagens me marcaram a ponto de me inspirarem a ficcionalizar sobre elas. Seja a mítica cartomante Maria da Ponte, que conheci numa cidadezinha no Paraná, a enigmática fazenda fantasma, que me levou a escrever o conto "A saga dos Laurentis", ou o drama da adolescente deprimida que descascava laranjas que me inspirou a escrever o conto "Pedra Azul":

Sentada na cadeira, usando um vestido de algodão branco, com os pés descalços sobre o chinelo, Maria Pedra descascava laranjas. $\mathrm{O}$ facão estava muito bem amolado, com o corte no ponto. A moça, que sangrou com treze anos, tem uma panela apoiada entre as coxas grossas e virgens. Ali ela guarda o que depois vai virar um doce melado. ${ }^{2}$

De mãos dadas com a realidade e a ficção, com o jornalismo e a literatura caminhei carregando na cachola perguntas sem respostas e dúvidas que me lançavam sempre ao limiar. Antonio Candido, num célebre ensaio, pergunta:

De onde parte a invenção? Qual a substância de que são feitas as personagens? Seriam, por exemplo, projeção das limitações, aspirações, frustrações do romancista? Não, porque o princípio que rege o aproveitamento do real é o da modificação, seja por acréscimo, seja por deformação das pequenas sementes sugestivas. O romancista é incapaz de reproduzir a vida, seja na singularidade da vida, seja na singularidade dos indivíduos, seja na coletividade dos grupos. [...] Na medida que quiser ser igual à realidade o romance será um fracasso; a necessidade de selecionar afasta dela e leva o romancista a criar um mundo próprio, acima e além da ilusão de fidelidade. ${ }^{3}$

Ao pé da Grande Montanha, também me deixei influenciar pelos gigantes do cânone. Ainda citando Antonio Candido,

A fertilização entre os textos literários é e sempre foi um dos meios mais correntes de composição, havendo épocas, como o Classicismo nas literaturas ocidentais modernas, nas quais o

\footnotetext{
${ }^{2}$ MELLO, 1995, p. 34.

${ }^{3}$ CANDIDO, 2002, p. 67.
} 


\section{Arquivo Maaravi}

autor timbra em deixar clara a sua dívida e praticar a imitação como quem procura fundamento e nobreza para o que escreve. ${ }^{4}$

Mas, sem desvalorizar o valor dos autores canônicos, não posso negar que a ficcionista que mais me inspirou até agora foi a REALIDADE e a sua implacável cumplicidade com o Tempo.

O poeta brasileiro Manoel de Barros (1916-2014) enxergou com genial clareza esse pacto entre as horas e o real. No poema "O menino que carregava água na peneira", o poeta escreveu: "A mãe falou:/ Meu filho você vai ser poeta./ Você vai carregar água na peneira a vida toda./ Você vai encher os/ vazios com as suas/ peraltagens/ e algumas pessoas/ vão te amar por seus/ despropósitos." 5

Manoel de Barros tem toda razão. Afinal, em tempos de verdades cada vez mais provisórias, só mesmo a subjetividade consegue vencer a finitude. As horas derretem muito mais rapidamente do que as geleiras... Difícil segurá-las na peneira, não é Manoel? Só param na mão da poesia. Que venham os poetas e os ficcionistas para guardar nas palavras o que já se faz fugaz.

Convidei o esquecimento para outro duelo quando me lancei na escritura do meu segundo livro, Eny e o Grande Bordel Brasileiro, publicado pela primeira vez em 2002, pela editora Objetiva, e relançado em 2015, pela editora Planeta. De tanto ouvir histórias dos moradores de Bauru sobre Eny Cezarino - a cafetina paulistana que comandou um bordel de luxo na cidade durante mais de vinte anos -, me despi de todo o preconceito e ousei escrever a primeira biografia de uma prostituta brasileira. Quebrei paradigmas porque até então o usual era um biógrafo querer associar o seu nome a uma grande figura que lhe agregasse "valor" intelectual. Lugar comum. Parti na contramão e transformei a mulher "sem valor social" em personagem de um bestseller que ficou cinco meses na lista dos livros mais vendidos da revista Veja e conquistou o segundo lugar no Prêmio Jabuti na categoria melhor reportagem/biografia. A produtora de cinema Casablanca comprou os direitos audiovisuais e logo o livro se tornará uma série de TV.

Mais uma vez meu processo criativo partiu do meu quintal, da minha aldeia, espaço que eu observava como uma ave de rapina em longos e silenciosos voos. Não cheguei a conhecer Eny pessoalmente. Mudei-me para Bauru em 1988, no ano seguinte à morte dela. Encontrei uma cidade praticamente enlutada. Afinal, Bauru perdera a sua principal atração turística e um dos personagens mais polêmicos. Visitei o que tinha sobrado do bordel algumas vezes, ouvi dezenas de depoimentos, recolhi fotografias, cartas e cartões escritos por Eny e por seus amores, vasculhei os arquivos dos jornais e revistas...

\footnotetext{
${ }^{4}$ CANDIDO, 2004, p. 43.

${ }^{5}$ BARROS, 2010, p. 469.
} 


\section{Arquivo Maaravi}

Ao escrever sobre uma mulher marginalizada eu também quis trabalhar a tolerância e mostrar que, por mais criminosa que ela fosse - afinal explorar a prostituição é crime em muitos países -, Eny também tinha um lado humano: fazia gordas doações a asilos e orfanatos, além de pagar funeral digno aos mendigos que morriam largados à má sorte nas ruas da cidade. Até presidentes da República visitaram Eny em busca de apoio político para os seus partidos e candidatos:

Isso aqui é um Palácio. Não sabia que em Bauru existiam áreas palacianas. O que meus inimigos vão dizer se me virem aqui, que me embriaguei? Que me apaixonei? Essas foram, segundo Nicola Avalone Júnior, as primeiras palavras que Jânio Quadros pronunciou quando entrou no bordel de Eny em agosto de 1982. ${ }^{6}$

O processo criativo do meu terceiro livro, A travessia da terra vermelha - uma saga dos refugiados judeus no Brasil, foi bem semelhante. Em 2003, quando comecei as pesquisas que resultaram nesse romance, publicado pela primeira vez em 2007, pela editora Novo Século, e em 2017, pela Companhia Editora Nacional, fui levado a conhecer o drama das famílias judaicas refugiadas do nazifascismo. Fui guiado pela curiosidade e pela alegria de ter achado uma joia rara, de estar diante de uma narrativa praticamente inédita até então: a história real de um plano de fuga que garantiu a dezenas de judeus passagem para o sertão do Paraná durante o horror nazista na Alemanha. Uma saga que eu chamo de "A lista de Schindler do Brasil".

Os refugiados foram salvos pela construção de uma ferrovia brasileira. Driblaram a perseguição hitlerista, orientados pelo então deputado alemão atuante na República de Weimar, Yohannes Schauff (o "Oskar Schindler" de Rolândia), que naquela época também estava sendo perseguido pelo Terceiro Reich. Os judeus compravam ferro da indústria alemã, revendiam para os construtores da ferrovia no Brasil e, em troca, recebiam como pagamento vales-terra, que lhe garantiam a propriedade de imensas fazendas no interior do Paraná.

Além do interesse em contar e trazer à luz essa saga real e cinematográfica, também fui levado a escrevê-la movido, especialmente, pelo desejo de combater o esquecimento e resgatar a história de dezenas de famílias perseguidas pelo hitlerismo, além de multiplicar o número testemunhas desse passado vivo que nos remete ao Holocausto enquanto fenômeno político e crime contra a Humanidade.

Lyslei Nascimento, no ensaio O museu, a Shoah e a cena da rememoração, chama a atenção para a urgência e a importância de os escritores contemporâneos manterem acesa a chama da lembrança por meio da ficção:

A Segunda Grande Guerra e as suas atrocidades estão cada vez mais distantes do homem contemporâneo. De uma certa forma, os relatos sobre a Shoah que ainda hoje são produzidos lutam

${ }^{6}$ MELLO, 2015, p. 352. 


\section{Arquivo Maaravi}

contra uma amnésia, que ameaça e, ao mesmo tempo, reinventa a memória. Os sobreviventes estão envelhecendo e o testemunho daqueles que viveram, viram ou ouviram a catástrofe está se perdendo com eles, mas as perguntas continuam a serem feitas. A ameaça do esquecimento surge, sobretudo, se se fizer da memória um peso morto, uma visita melancólica e ritualizada a um museu onde se guardam os restos de uma cultura ou de um tempo desaparecido. ${ }^{7}$

Escrever sobre o horror nazista já é um desafio hercúleo: como ficcionalizar, a partir de dados históricos que rastreiam um atributo tão dolorosamente humano, a crueldade? Testemunhar também é transpor a barreira do até então indizível. E diante dos relatos, quantas dúvidas e desafios! Como erguer um romance sobrepondo paixões, amores dissolvidos, famílias destroçadas, destinos intercalados em camadas carregadas de significados tendo como fulcro o homem como vítima e protagonista da História, ou mesmo a trajetória de judeus que reinventaram suas existências sem perder sua ancestralidade?

Rolândia se revelou para mim um sertão ilustrado, um oásis cultural em pleno deserto sertanejo:

O mesmo fazia com as obras literárias que tirava do buraco para ler. O que não fazemos pelo amor à leitura, não é, Dr. Volk?, dizia Bernardo ao vizinho. Fiquei sabendo que o senhor também tem uma grande biblioteca enterrada. Não só eu como o Thomas Schneider, os Henschel, os Prustel e até os Luft Hagen e o Oswald Nixdorf, revelou doutor Volk. Pois veja o senhor se todos esses livros germinassem... Que felicidade nos daria, não é mesmo? Essa terra toda se transformaria numa grande lavoura literária, livros nasceriam e cresceriam como milho, algodão, café... E nós colheríamos histórias, ideias, conhecimento, filosofia... Pois que fiquem plantados nesse solo por quanto tempo for necessário, afirmou doutor Volk, ninguém há de poder nos acusar de não ter plantado nada que preste no Brasil. De Goethe a Dostoiévski, James Joyce, Proust, Thomas Mann, Aristóteles, Platão, Marx, Victor Hugo, Flaubert, Cervantes, Shakespeare, Rilke, Schiller, Fernando Pessoa, Virginia Woolf, semeei o melhor da literatura universal nesta terra, disse o advogado. Que brotem os livros! Que brotem os livros! Disseram os dois vizinhos ao mesmo tempo. ${ }^{8}$

\footnotetext{
${ }^{7}$ NASCIMENTO, 2007, p. 104.

${ }^{8}$ MELLO, 2017, p. 101.
} 
Enquanto pesquisava essa história, alguns refugiados pediram para que eu trocasse seus verdadeiros nomes por nomes fictícios. Mas, além de respeitar o desejo dos personagens reais dessa saga, também preferi fazer essa troca por concordar com o pensamento de Primo Levi no ensaio Escrever um romance:

Do mesmo modo que é impossível transformar uma pessoa de carne e osso em personagem, fazer dela uma biografia objetiva e não distorcida, também é impossível fazer a operação inversa, cunhar um personagem sem transplantar para dentro dele além do seu humor de autor, fragmentos de pessoas que você encontrou e de outros personagens. ${ }^{9}$

O meu quarto livro, o romance Mestiços da Casa Velha, também nasceu de um encontro REAL. Desta vez com um professor de língua portuguesa, num boteco paratiense, durante a Festa Literária Internacional de Paraty (FLIP), em 2004. Na época, eu estava na cidade fluminense trabalhando como repórter do Canal Futura Fundação Roberto Marinho. O professor negro se apresentou como Bento - "Pode me chamar de Bentinho", explicou. Imediatamente, o jovem educador me remeteu ao famoso personagem machadiano. No dia seguinte, fui visitá-lo próximo à marina de Paraty no casarão que pertenceu à família de Júlia Mann ${ }^{10}$, mãe de Thomas Mann. Dentro do imóvel, a ideia do romance surgiu. “Thomas Mann aqui, Machado de Assis no boteco... Este encontro improvável pode ser inspirador..." Passei os próximos dias andando pelas ruas de Paraty, ouvindo as vozes dos personagens do romance. O Bentinho real, professor, virou personagem assim como o casarão de Júlia Mann:

Estava entregue à vontade de três implacáveis jogadores dispostos a tudo para aprisioná-la. A morte sedutora a estimulava a pular no abismo imenso, com eco e tudo, que havia no seu próprio coração. A loucura valia-se da imaginação, das ideias e da luz que havia dentro da caça para atraí-la para a armadilha e finalmente tê-la nas mãos. Já a semente sabia que só teria seus dias de King Kong se expulsasse a moça definitivamente da célula que a gerou e onde ela resistia em

\footnotetext{
${ }^{9}$ LEVI, 2016, p. 177-178.

${ }^{10}$ Júlia da Silva Bruhns Mann nasceu em 14 de agosto de 1851, em Paraty-RJ. Era filha de Johann Ludwig Herman Bruhns, um fazendeiro que possuía plantações de cana de açúcar entre Santos e Rio de Janeiro, e de Maria Luísa da Silva, brasileira com sangue português e indígena, que faleceu quando Júlia tinha 5 anos. A ausência da mãe fez o patriarca enviar toda a família (Júlia tinha três irmãos e uma irmã), meses depois, para Lübeck, cidade ao norte da Alemanha. Quando tinha 17 anos, Júlia casou-se com o senador, cônsul e comerciante alemão Johann Henrich Mann. O casal teve cinco filhos, entre eles aquele viria a se tornar Prêmio Nobel de Literatura, Thomas Mann.
} 


\section{Arquivo Maaravi}

permanecer depois de muitas idas e vindas. Mar placentário mar... Quem mais além de você saberá resgatar e guardar o segredo do orgasmo dos bebês? ${ }^{11}$

Escrever ficção é um impulso complexo e composto de uma infinidade de sentidos. Um arrebatamento quase incontrolável, creio; algo mais do Diabo do que de Deus, que levou, por exemplo, a escritora brasileira, até então mais famosa do que lida Hilda Hislt, a ser estigmatizada por sua fama de maldita e obscena.

Homenageada nessa semana na FLIP, em Paraty, Hilda não se cansava de dizer aos jornalistas que passou os 40 primeiros anos de sua carreira pesquisando, estudando o cânone, "trabalhando com seriedade" para conquistar a admiração e o respeito da crítica e do mercado editorial. Nesse caso, a autora deixou bem claro que sempre escreveu para ser reconhecida, consagrada como escritora e, quem sabe, entrar para o cânone. O desejo hilstiano pelo sucesso era tão avassalador que a escritora chocou a todos em 1990 quando decidiu protestar e agredir todos os editores que lhe disseram $\mathrm{NÃO}$, publicando O caderno rosa de Lori Lamby - escandalosas memórias sexuais de uma menina de 8 anos, sem o menor pudor e sem reservas no emprego de palavras obscenas.

Numa entrevista à TV Cultura, em 1990, Hilda revelou a razão que a fez abandonar e trocar a literatura, que naquela época era considerada "séria", pela literatura pornográfica:

É um ato de agressão. O Caderno Rosa de Lori Lamby não é um livro é uma BANANA que estou dando para os editores e para o mercado editorial. Os editores te cospem na cara. Foi o que fizeram comigo. O único que não o fez foi Massao Ohno! Um escritor deseja ser lido. Essa é a meta e a vontade de um escritor. Eu espero que desta vez me leiam seja na cápsula, no bonde, no avião e nos banheiros também. ${ }^{12}$

Faço questão de citar Hilda porque penso que ela nos deixa uma lição: a lição de que a literatura não pode ser encarada como prisão. Muito pelo contrário. Ela deve ser o principal endereço da liberdade. Para surpresa de muitos, Hilda fez do erotismo o caminho para atingir o sagrado, como esclarece a pesquisadora Eliane Robert Moraes: “Em Lory Lamb, Hilda excede a intenção obscena para revelar sua notável capacidade de jogar com os limites da linguagem". ${ }^{13}$

Hilda e tantos outros ficcionistas desafiaram a si mesmos para se reinventar como escritores e seguir escrevendo. No cânone há chaves fundamentais que tanto podem nos ajudar a entender os diferentes motivos que levam um autor a escrever, como

\footnotetext{
${ }^{11}$ MELLO, 2008, p. 10.

${ }^{12}$ HILST, 1990, TV CULTURA-SP.

${ }^{13}$ MORAES, 2018, p. 20-23.
} 


\section{Arquivo Maaravi}

também o processo criativo de cada um. Nesse sentido, Harold Bloom, em $A$ anatomia da influência, nos ensina:

Meus alunos me perguntam com frequência por que grandes escritores não podem recomeçar do zero sem nenhum passado nas costas. Só lhes posso dizer que simplesmente não funciona assim, já que na prática, como no vocabulário de Shakespeare, inspiração significa influência. Ser influenciado é ser ensinado... ${ }^{14}$

Sem ir muito longe, visitemos Machado de Assis. Ao escrever o ensaio Instinto de nacionalidade, em 1873, ele deixa bem claro as expectativas que tinha para a literatura brasileira e para a sua missão como escritor e ficcionista: "O que se deve exigir do escritor, antes de tudo, é certo sentimento íntimo, que o torne homem do seu tempo e do seu país, ainda quando trate de assuntos remotos no tempo e no espaço."15

Apesar de ter sido escrito há 145 anos, quase um século e meio atrás, o pensamento do maior escritor brasileiro continua vivo e muito atual. É um pensamento que se renova e se conecta aos ideais de grandes escritores do mundo, como o israelense Amos Oz. Em uma entrevista ao jornal Zero Hora, publicada em 23 em junho de 2017, ele esclareceu:

Penso que romances, contos, poesia, podem abrir para os leitores diversas janelas para o mundo exterior e para dentro de si mesmo. [...] Eu sou um escritor, trabalho com palavras todos os dias, do mesmo modo que um carpinteiro trabalha com a madeira ou um pedreiro com tijolos. [...] É meu dever gritar a cada vez que vejo alguém usando uma linguagem contaminada. Quando algumas pessoas chamam outras de 'estrangeiros indesejáveis', 'elementos negativos', 'câncer social' ou 'parasitas', sei que é sempre aí que começam a violência, a perseguição e a crueldade. Daí meu senso de dever de trabalhar como o corpo de bombeiros do idioma, ou como um detector de fumaça, eu preciso gritar 'fogo'! sempre que leio ou ouço essas palavras que, mais cedo ou mais tarde, vão gerar violência. ${ }^{16}$

O premiado ficcionista americano Jonathan Franzen também concorda com a comparação que Amos $\mathrm{Oz}$ faz da figura do escritor com a do bombeiro. Recentemente, ele usou como título de um ensaio a seguinte pergunta: "Tarde demais para salvar o mundo?" E escreveu:

\footnotetext{
${ }^{14}$ BLOOM, 2011, p. 23-24.

${ }^{15}$ ASSIS, 2004, p. 804.

$16 \mathrm{OZ}, 2017$.
} 


\section{Arquivo Maaravi}

As causas que realmente valem a pena - da preservação dos pássaros à resistência ao governo Trump - empurram o escritor para o papel de ensaísta - uma espécie de bombeiro que corre em direção às chamas da vergonha enquanto todos tentam escapar delas. ${ }^{17}$

Primo Levi, no ensaio "Por que se escreve?", publicado em $O$ ofício alheio, destacou nove "motivações" que, na opinião dele, podem levar uma pessoa a escrever. Acredito que a grande maioria dos escritores se identifica com a maior parte delas. $\mathrm{E}$ três dessas motivações se aproximam do pensamento humanista de Machado de Assis, Amos $\mathrm{Oz}$ e Jonathan Franzen. São elas: para ensinar algo a alguém; para melhorar o mundo; e para difundir as próprias ideias.

Escritores compromissados com o coletivo são raros hoje em dia. Em Israel, por exemplo, como nos esclarece Nancy Rozenchan, no ensaio "As múltiplas faces da identidade judaica na literatura hebraica do século $X X^{\prime \prime}$ :

Existia um item do regimento da Associação dos Escritores dos kibutzim e Kvutsot de 1955, que rezava o seguinte: o escritor deve buscar concomitantemente à integridade de sua vida, condições de trabalho e arte, de modo que o anseio do desenvolvimento pessoal completo não seja superior à dimensão do ideal social, e que a ideia coletiva lhe seja tão preciosa quanto o anseio artístico. ${ }^{18}$

Rozenchan ainda prossegue:

Como estas palavras, repetidas 60 anos mais tarde parecem ser provenientes de algum outro planeta, em virtude do que ocorre atualmente na literatura hebraica - com obras voltadas para o individuo e um entrincheiramento nas particularidades do diaa-dia, distantes dos ideais coletivos já quase esquecidos. ${ }^{19}$

Penso que não há como refletir e repensar o processo criativo e o ato de escrever sem viajar à semente do Judaísmo. A memória é a casa da alma, escreveu o pensador e filósofo Santo Agostinho. Acredito que a memória é a casa do povo judeu, uma metáfora quase perfeita para nos referirmos à mítica terra prometida e ao Estado de Israel. Retornar à memória é também regressar à terra prometida com todos os significados e sentidos que ela traz aparelhados numa viagem incerta e sem porto seguro.

\footnotetext{
17 FRANZEN, 2018, p. 130.

${ }^{18}$ ROZENCHAN, 2004, p. 9.

${ }^{19}$ ROZENCHAN, 2004, p. 9.
} 


\section{Arquivo Maaravi}

Escrevo para não me esquecer da minha própria humanidade, para não desaprender o caminho mais perigoso e desafiador que pode me conduzir ao mitológico, movediço e sagrado território da memória onde é possível encontrar a matéria-prima da mais cara de todo escritor: o humano desprovido de disfarces.

Como escreveu Rilke nas cartas ao jovem poeta Franz Kappus, é preciso

entrar em si e examinar as profundidades de onde jorra a sua vida; na fonte desta é que encontrará a resposta à questão de saber se deve criar. [...] Aceite o destino e carregue-o com seu peso e sua grandeza, sem nunca se preocupar com recompensa que possa vir de fora. O criador, com efeito, deve ser um mundo para si mesmo e encontrar tudo em si e nessa natureza a que se aliou. $^{20}$

Tudo que, na maioria das vezes, revela-se uma grande ausência de si mesmo e o eterno e doloroso embate do escritor contra o esquecimento da sua própria humanidade.

\section{Referências}

MACHADO DE ASSIS, Joaquim Maria. Instinto de nacionalidade. In: Obra completa em 4 volumes. v. 3. Rio de Janeiro: Editora Nova Aguilar, 2004.

BARROS, Manoel de. O menino que carregava água na peneira. In: . Poesia completa. São Paulo: Editora Leya, 2010.

BLOOM, Harold. A anatomia da influência. Trad. Ivo Korytowski e Renata Telles. Rio de Janeiro: Editora Objetiva, 2011.

CANDIDO, Antonio. Ressonâncias. In: . O albatroz e o chinês. Rio de Janeiro: Editora Ouro sobre Azul, 2004. p. 43-51.

CANDIDO, Antonio. A personagem do romance. In: . A personagem de ficção.

São Paulo: Editora Perspectiva, 2002. p. 53-80.

ECO, Umberto. Seis passeios pelos bosques da fiç̧ão. Trad. Hildegard Feist. São Paulo: Companhia das Letras, 2002.

FRANZEN, Jonathan. Tarde demais para salvar o mundo? Revista Serrote, n. 28, p. 130-152, 2018.

HILST, Hilda. Entrevista concedida em 1990, por ocasião do lançamento de O caderno rosa de Lori Lamby. TV Cultura - SP. Disponível em: <https://www.youtube.com/watch?v=5yeFhO4G2OQ>. Acesso em: jan. 2019.

LEVI, Primo. O ofício alheio. Trad. Silvia Massimini Felix. São Paulo: Editora UNESP, 2016.

${ }^{20}$ RILKE, 2003, p.28. 


\section{Arquivo Maaravi}

Revista Digital de Estudos Judaicos da UFMG

ISSN: 1982-3053

MELLO, Lucius de. Um violino para os gatos. São Paulo: Editora Maltese, 1995.

MELLO, Lucius de. Eny e o Grande Bordel Brasileiro. São Paulo: Editora Planeta, 2015.

MELLO, Lucius de. A travessia da Terra Vermelha. São Paulo: Companhia Editora Nacional, 2017.

MELLO, Lucius de. Mestiços da Casa Velha. São Paulo: Editora Novo Século, 2008.

MORAES, Eliane Robert. As faces espelhadas de Eros. Revista Cult, n. 233, São Paulo: Editora Bregantini, 2018.

NASCIMENTO, Lyslei. O museu, a shoah e a cena da remoração. Arquivo Maaravi. Revista Digital de Estudos Judaicos da UFMG. Belo Horizonte, v. 1, n. 1, p. 98-113, 2007. Disponível em:

http://www.periodicos.letras.ufmg.br/index.php/maaravi/article/view/974 >. Acesso em: 13 set. 2019.

OZ, Amós. GaúchaZH, Porto Alegre-RS, 26 jun. 2017. Entrevista. Disponível em: $<$ https://gauchazh.clicrbs.com.br/cultura-e-lazer/noticia/2017/06/muitos-dos-maioresmales-deste-mundo-comecam-com-a-corrupcao-da-linguagem-dizamos-oz9823388.html>. Acesso em: 15 jan. 2019.

RILKE, Rainer Maria. Cartas a um jovem poeta. Trad. Cecília Meireles e Paulo Ronái. São Paulo: Editora Globo, 2003.

ROZENCHAN, Nancy. As múltiplas faces da identidade judaica na literatura hebraica do século XX. In: . Literatura Hebraica: vertentes do século XX. São Paulo: Editora Humanitas, 2004. p. 9-44.

Recebido em: 20/09/2019.

Aprovado em: 20/10/2019. 